\title{
Combination of enzymatic hydrolysis and ethanol organosolv pretreatments : effect on lignin structures, delignification yields and cellulose-to-glucose conversion
}

\author{
$\underline{\text { Authors : Patrick Obama }}{ }^{a}$, Guillaume Ricochon ${ }^{b}$, Lionel Muniglia ${ }^{b}$, Nicolas Brosse $^{a}$ \\ Affiliations :
}

a) Laboratoire d'Etude et de Recherche sur le MAteriau Bois, Faculté des Sciences et Techniques, Université de Lorraine, Bld des Aiguillettes, BP 70236, 54506 Vandoeuvre-lès-Nancy cedex, France

b) Laboratoire d'Ingénierie des Biomolécules (LIBio), Université de Lorraine, 2 av. de la forêt de Haye, BP 172, F-54505 Vandoeuvre lès Nancy Cedex, France

* Corresponding author. E-mail address: Nicolas.Brosse@ @ermab.uhp-nancy.fr ; tel +33383684862 ; fax + 333
83684498

\section{Abstract}

Enzymatic pre-hydrolysis using the industrial enzymatic cocktail Cellulyve $®$ was assessed as a first step in a pretreatment process of Miscanthus biomass involving an aqueous-ethanol organosolv treatment. ${ }^{13} \mathrm{C}$ and ${ }^{31} \mathrm{P}$ Nuclear Magnetic Resonance and Size Exclusion Chromatography were used to analyze the cellulose and lignin before and after treatment. It was demonstrated that despite a very low impact on the fibre structure (observed by Scanning Electon Microscopy) and composition (in terms of sugars and polyphenolics content), the enzymatic pre-treatement disrupted the lignocellulosic matrix in a considerable extend. This weakening permitted to enhance the removal of lignin during the organosolv pulping and the hydrolysability of the residual cellulosic pulp for the production of monomeric glucose. Using this combined treatment, a delignification yield of $93 \%$ and an enzymatic cellulose-to-glucose conversion of $75 \%$ were obtained.

Keywords : Enzyme, miscanthus, pretreatment, bioethanol 


\section{Introduction}

4 Utilization of lignocellulosic feedstock for fuel and chemical production requires the

5 development of pretreatment technologies necessary to break up lignin structures, to separate

6 the three biopolymers (lignin, cellulose and hemicelluloses) and to enhance enzyme 7 digestibility of cellulose (FitzPatrick, 2010 ; Brodeur, 2011). Different kinds of physical 8 and/or chemical pretreatments have been proposed for the conversion of wood and 9 agricultural wastes. Among these methods, the ethanol organosolv process is promising since 10 it allows clean fractionation of the biomass. This technology has already been developed at an 11 industrial scale (Alcell® process) and recently has been evaluated and optimized for 12 delignification of softwood, hardwood and crops (Pan et al., 2006, 2007 ; Brosse et al., 2009). 13 One of the major goals of optimizing a pretreatment process is the full recovery of the 14 feedstock through optimum utilization of all lignocellulosic components ; however, conditions 15 known to promote lignin depolymerisation also cause degradation of hemicellulose sugars 16 into furfural, hydroxymethyl furfural (HMF) and carboxylic acids. These degradation 17 products inhibit downstream processing (Thomsen at al., 2009). To circumvent this drawback, two-stage pretreatments were described. In the 1st step hemicelluloses is hydrolysed and in the second step the solid material from the first step is treated at higher severity. This approach can result in higher sugar yields than one-step pretreatment. Thus, fungal (Munos et 21 al., 2007) or dilute sulphuric acid prehydrolysis (Brosse et al, 2009; Patel and Varshney, 22 1989) before an organosolv treatment demonstrated a favorable effect on delignification.

23 In previous studies, autohydrolysis of Miscanthus straw was assessed as a first step of a pre24 treatment process involving an aqueous-ethanol organosolv treatment (El Hage et al., 2010a). 25 During autohydrolysis, acetic acid is produced from xylans and enables the hydrolysis and the 
1 dissolution of a great part of hemicellulose. It also permits the cleavage of lignin-carbohydrate

2 bonds (Garrote et al., 2001, 2002 ; Lee et al, 2009). After autohydrolysis, delignification

3 reactions are accelerated and the solubility of lignin in a subsequent extraction with aqueous

4 organic solvent is increased. The autohydrolysis process also impacts lignin structure (El

$5 \quad$ Hage et al., 2010a). During autohydrolysis lignin homolytical fragmentation should promote

6 repolymerisation reactions which negatively affect the subsequent organosolv delignification

7 step. Furthermore, autohydrolysis conditions lead to a loss of polysaccharides through

8 dehydration and degradation reactions and generate weak acids, furfural and 5-

9 hydroxyfurfural which negatively impact microorganisms involved in the fermentation step

10 (Palmqvist \& Hahn-Hagerdal, 2000).

11 Enzymatic hydrolysis is now usually employed in many industrial processes. In cellulosic

12 ethanol industry and in most studies on the conversion of biomass to fuel, enzymes are usually added at the end of the process to complete the conversion of cellulose to glucose

14 (Katzen \& Schell, 2006). In the development of sustainable processes, the implementation 15 methods reducing the amount of chemicals and energy consumption are of interest and thus, it 16 may be appropriate to carry out pre-treatments enzymatically.

17 In the present study, pretreatment of lignocellulosic biomass was carried out involving a 18 biological prehydrolysis step using an industrial enzymatic cocktail mainly composed of 19 cellulase and xylosidase activities and an ethanol organosolv treatment performed at low 20 severity. Enzymatic prehydrolysis was compared to autohydrolysis, a hydrothermal treatment 21 previously studied in terms of delignification yields and cellulose-to-glucose conversion. The 22 impact of the processes on the cellulose and lignin structures was investigated. The purpose of 23 this 2-steps process is to propose an optimized method for the separation of lignocellulosic 24 components from lignocellulosic feedstock. 


\section{2. Materials and Methods}

2 Miscanthus was harvested in the spring 2009 at Courcelles-Chaussy (France). The dried

3 Miscanthus biomass was milled to a particle size of 1-3 mm using a Wiley mill and stored at

$4 \quad 5{ }^{\circ} \mathrm{C}$. All chemical reagents used in this study were purchased from Sigma Aldrich and VWR

5 (France) and used as received. Dried matter contents were determined using a moisture

6 balance, KERN MRS 120-3 Infra-red moisture analyser (drying at $105^{\circ} \mathrm{C}$ to constant weight).

7 The effective dry matter content of raw Miscanthus biomass was $96 \%$.

\subsection{Enzymatic activities}

Cellulyve ${ }^{\circledR}$, a commercial Trichoderma reesei cellulase (E.C. 3.2.1.4) preparation was kindly

11 provided by Lyven (Colombelles, France). The cellulase activities were quantified following IUPAC recommended procedures (T.K. Ghose, 1987). Endo-glucanase (E.C. 3.2.1.4), 1,4- $\beta$ cellobiosidase (E.C. 3.2.1.91) and $\beta$-glucosidase (E.C. 3.2.1.21) activities were respectively measured on carboxymethylcellulose (CMC, Sigma C8758, $10 \mathrm{IU} / \mathrm{ml})$, filter paper (Whatman 3001-917, 4 IFPU/ml) and cellobiose (Serva, 16400, $7 \mathrm{IU} / \mathrm{ml}$ ) as substrates. After hydrolysis of polysaccharides, reducing sugar content was determined by the Nelson-Somogyi method (Somogyi, 1952). Hemicellulase activities were assayed in a reaction mixture containing 900 $\mu \mathrm{L}$ of the appropriate substrate $(1 \mathrm{~g} / \mathrm{L})$ and $100 \mu \mathrm{L}$ of dilutedenzymatic preparation both prepared in citrate buffer $(0.05 \mathrm{M}, \mathrm{pH} 4.8)$. The hydrolysis was followed at $50^{\circ} \mathrm{C}$ as long as necessary to measure the kinetic (linear part of curve) at $405 \mathrm{~nm}$. $\alpha$-arabinosidase (E.C. 3.2.1.99), $\beta$-xylosidase (E.C. 3.2.1.37) and $\beta$-galactosidase (E.C. 3.2.1.23) activities were determined using $p$-nitrophenyl- $\alpha$-L-arabinofuranoside (Sigma, 122H5031), $p$-nitrophenyl- $\beta$ D-xylopyranoside (Sigma 125K4054) and $p$-nitrophenyl- $\beta$-D-galactofuranoside (Sigma 92H5003) substrates respectively. Activities were calculated following the release of free $p$ - 
$1 \mathrm{IU} / \mathrm{ml}$ for $\alpha$-arabinosidase and $\beta$-xylosidase respectively; no activity was detected for $\beta$ -

2 galactosidase activity. No pectinolytic activity (E.C. 3.1.1.11, E.C. 3.2.1.15) was detected in

3 the preparation.

\subsection{Hydrothermal processing / Autohydrolysis}

6 Miscanthus samples 1-3 mm particle size (20 g dried matter, raw material) were loaded into a

7 0.6-L stainless steel pressure Parr reactor with a Parr 4842 temperature controller (Parr 8 Instrument Company, Moline, IL) and were supplemented with an appropriate amount of 9 deionized water to make a final solid to liquid ratio of $1 / 9$, taking into account the moisture 10 content of the sample. The mixture was heated at $150^{\circ} \mathrm{C}$ with continuous stirring for $8 \mathrm{~h}$ (time 11 zero was set when the preset temperature was reached with eating rate of $5 \mathrm{~K} / \mathrm{min}$ ). At the 12 end of each reaction, the reactor was cooled and the liquid phase was recovered by filtration 13 through. Solid residue was washed with $70^{\circ} \mathrm{C}$ water $(3 \times 50 \mathrm{ml})$ and a portion of solid residue 14 and liquid were stored in a freezer at $-5^{\circ} \mathrm{C}$ before analysis.

15

\section{2.3. Enzymatic prehydrolysis step}

17 Ten g of Miscanthus biomass (dry weight) were loaded into an Erlenmeyer flask containing $100 \mathrm{~mL}$ of deionized water. Five \% (w/w based on dry mass of Miscanthus) of Cellulyve® 19 were added. The flask was placed in an incubator at $50^{\circ} \mathrm{C}$ and shaken at $140 \mathrm{rpm}$. After each reaction, the mixture was centrifuged at $2000 \mathrm{x}$ g during $5 \mathrm{~min}$ and the solids were washed

21 three times ( $3 \times 100 \mathrm{~mL})$ with deionized water. A few $\mathrm{mL}$ of the aqueous phase were kept at $5^{\circ} \mathrm{C}$ for subsequent chemical analysis.

\section{$24 \quad$ 2.4. Organosolv treatment}


1 Twenty-five grams (dry weight) of native or autohydrolysed Miscanthus biomass was milled

$2(200 \mu \mathrm{m})$ and mixed with $80 \%$ aqueous ethanol $\left(\mathrm{EtOH} / \mathrm{H}_{2} \mathrm{O}: 8 / 2 \mathrm{v} / \mathrm{v}\right)$ and $0.5 \%$ or $1 \%$ w/w

3 (based on raw material dried mass) sulfuric acid as a catalyst. The mixture was heated at

$4150^{\circ} \mathrm{C}$ or $170^{\circ} \mathrm{C}$ for $30 \mathrm{~min}$ or $60 \mathrm{~min}$. The solid-to-liquid ratio used was $1: 8$. Treatments

5 were carried out in a 0.6 L stainless steel pressure Parr reactor with a Parr 4842 temperature

6 controller (Parr Instrument Company, Moline, IL). The reaction mixture was heated at a rate

7 of $5 \mathrm{~K} / \mathrm{min}$ with continuous stirring. At the end of the treatment, the pretreated Miscanthus

8 biomass was washed with $60^{\circ} \mathrm{C}$ ethanol-water $(8: 2,3 \times 50 \mathrm{~mL})$ and air-dried overnight. The

9 washes were combined, and three volumes of water were added to precipitate the ethanol 10 organosolv lignin (EOL), which was collected by centrifugation at $2000 \mathrm{x} g$ during $5 \mathrm{~min}$ and

11 then air-dried. A portion of each the solid residue and the liquid was separated and stored in a

12 freezer at $-5^{\circ} \mathrm{C}$ before analysis.

\subsection{Cellulose extraction}

Holocellulose was isolated from the untreated Miscanthus particles, autohydrolysis and enzyme hydrolysis residues by repeatedly treating with a mixture of acetic acid and sodium chlorite until the sample had a very low Klason lignin content $(<1 \%)$. The holocellulose sample $(1 \mathrm{~g})$ was further treated with $50 \mathrm{~mL}$ of $\mathrm{NaOH}, 17.5 \%$ during $30 \mathrm{~min}$ at $25^{\circ} \mathrm{C}$. Fifty $\mathrm{mL}$ of deionized water was added and the resulting slurry was stirred at $25^{\circ} \mathrm{C}$ for $30 \mathrm{~min}$. The resulting cellulose was filtered, washed successively with $50 \mathrm{ml}$ of $1 \%$ acetic acid in water and with $100 \mathrm{~mL}$ of deionized water and then dried in an oven at $40^{\circ} \mathrm{C}$ overnight.

\subsection{Enzymatic hydrolysis (cellulose-to-glucose conversion)}

Enzymatic hydrolysis of raw and pretreated Miscanthus biomass was performed using

Celluclast ${ }^{\circledR}$ 1.5 L (E.C. 3.2.1.4) from Trichoderma reesei supplemented with $\beta$-glucosidase 
1 preparation (Novozym 188®, E.C. 3.2.1.21) from $\underline{\text { Aspergillus niger }}$ at a loading of 40 IFPU

2 and 80 IU per g cellulose respectively. Both enzyme preparations were purchased from

3 Novozymes (Bagsværd, Denmark). Enzymatic hydrolyses were performed at $2 \%$ (cellulose

$4 \mathrm{w} / \mathrm{v}$ ) in $100 \mathrm{~mL}$ of $50 \mathrm{mM}$ acetate buffer, $\mathrm{pH} 4.8$. The reaction mixtures were incubated at

$550^{\circ} \mathrm{C}$ in a rotary shaker at $170 \mathrm{rpm}$, sampled periodically and centrifuged $(2000 \mathrm{x} \mathrm{g})$ to

6 remove the insoluble materials for analysis. Glucose contents of the aqueous phase were

7 quantified using high-performance anion-exchange chromatography with pulsed

8 amperometric detection (HPAEC PAD) (section 2-7). Hydrolysis data are averages from

9 duplicate experiments.

\section{$11 \quad$ 2.7. Analytical Procedures}

12 A KERN MRS 120-3 Infra-red moisture analyser (drying at $105^{\circ} \mathrm{C}$ to constant weight) was used for moisture determination.

Ash content was determined (by calcination at $525^{\circ} \mathrm{C}$ for $5 \mathrm{~h}$ ).

Extractables were determined by extracting untreated Miscanthus biomass (50 g) with

16 dichloromethane (DCM, 1L), using a Soxhlet apparatus (volume $=2 \mathrm{~L}$ ) for $6 \mathrm{~h}$ (about 36 17 extraction cycles).

18 Carbohydrate and lignin contents were measured on extractive-free material, ground to pass a 40-mesh screen, according to the laboratory analytical procedure (LAP) provided by the National Renewable Energy Laboratory (NREL). Samples were hydrolyzed with $72 \%$

21 sulfuric acid for $1 \mathrm{~h}$ and autoclaved after being diluted to $3 \%$ sulfuric acid through the 22 addition of water. The autoclaved samples were filtered, and the dried residue was weighed to 23 give the Klason lignin content. Monosaccharide contents in the filtrate were quantified using 24 high-performance anion-exchange chromatography with pulsed amperometric detection 25 (HPAEC PAD). The acid-soluble lignin content was determined from absorbance at $205 \mathrm{~nm}$ 
1 according to Lin and Dence 1992. In brief, the lignin content in the filtrate was calculated

2 from the following expression of Beer's law : Lignin $(\mathrm{g} / \mathrm{L})=$ Absorbance $/ 110$. Furan

3 contents were estimated in the water-soluble fraction from the absorbance at 284 and $305 \mathrm{~nm}$

4 according to Martinez et al. (2000).

5 To determine the composition of the water-soluble fractions recovered after autohydrolysis, a

6 post hydrolysis was performed because of the presence of sugars in oligomeric forms. An 7 aliquot $(10.00 \mathrm{~mL})$ of the solution was freeze-dried, dissolved in deionized water $(10.00 \mathrm{~mL})$, and the post hydrolysis of oligosaccharides was accomplished by addition of $72 \% \mathrm{H}_{2} \mathrm{SO}_{4}$ (to obtain a $3 \%$ sulfuric acid solution $(348 \mu \mathrm{L})$. Regarding the liquid phase recovered after enzymatic treatments, production of monomeric sugars was observed (no increase in the sugar concentrations after post hydrolysis) and direct chromatographic analysis was performed. The monosaccharide contents were quantified using a high-performance anion-exchange chromatography with pulsed amperometric detection.

\subsection{High-performance anion-exchange chromatography}

Separation and quantification of neutral sugars were performed using a Dionex ICS-3000 system consisting of a SP gradient pump, an AS autosampler, an ED electrochemical detector with a gold working electrode, an $\mathrm{Ag} / \mathrm{AgCl}$ reference electrode and Chromeleon version 6.8 (Dionex Corp., USA). A Carbopac PA1 (4 x 250 mm, Dionex) column with a guard column (4 x $50 \mathrm{~mm}$, Dionex) was used as a stationary phase using isocratic conditions with $1 \mathrm{mM}$ sodium hydroxide as eluent. Eluents were prepared by dilution of a $46-48 \% \mathrm{NaOH}$ solution (PA S/4930/05 Fisher Scientific) in ultrapure water. All eluents were degassed before use by flushing with helium for $20 \mathrm{~min}$; subsequently they were kept under constant helium pressure (eluent degassing module, Dionex). After each run, the column was washed for 10 min with $200 \mathrm{mM} \mathrm{NaOH}$ and reequilibrated for $15 \mathrm{~min}$ with the starting conditions. Samples were 
1 injected through a $25-\mu \mathrm{L}$ full loop and separations were performed at $25{ }^{\circ} \mathrm{C}$ at a rate of 1

$2 \mathrm{~mL} / \mathrm{min}$. The pulse sequence for pulsed amperometric detection consisted of a potential of

$3+100 \mathrm{mV}(0-200 \mathrm{~ms}),+100 \mathrm{mV}$ integration $(200-400 \mathrm{~ms}),-2000 \mathrm{mV}(410-420 \mathrm{~ms}),+600 \mathrm{mV}$

4 (430ms), and -100mV (440-500ms).

\subsection{NMR and SEC analysis}

All NMR experiments were performed on a Bruker Avance-300 spectrometer operating at a frequency of $100.59 \mathrm{MHz}$ for ${ }^{13} \mathrm{C}$. Organosolv lignin $(100 \mathrm{mg}$ ) were dissolved in DMSO d6 $(0.50 \mathrm{~mL}) .{ }^{13} \mathrm{C}$ NMR spectra were acquired at $50{ }^{\circ} \mathrm{C}$ in order to reduce viscosity. Quantitative NMR spectra were acquired using an inverse-gated decoupling (Waltz-16) pulse sequence to 11 avoid Nuclear Overhauser Effect (NOE) effects. Ten thousand scans were collected with a 12 pulse delay of 12 s. ${ }^{13} \mathrm{C}$ data were processed offline using XWinNMR processing software.

$13{ }^{31} \mathrm{P}$ NMR spectra were acquired after derivatising $25 \mathrm{mg}$ lignin with 2-chloro-4,4,5,514 tetramethyl-1,1,3,2-dioxaphospholane (TMDP)(Granata and Argyropoulos, 1995).

15 The number average molecular weights $(\mathrm{Mn})$ and weight $(\mathrm{Mw})$ of lignin and cellulose were 16 determined after derivatization by size exclusion chromatography with a Dionex Ultimate173000 HPLC system consisting of an autosampler and a UV detector and using tetrahydrofuran as eluent. Standard polystyrene samples were used to construct a calibration curve. Data were collected and analysed with Chromeleon software version 6.8 (Dionex Corp., USA).

Cellulose and lignin samples were analysed after tricarbanilation (Foston and Ragauskas, $212010)$ and after acetylation respectively (El Hage et al., 2009).

\section{Results and discussion}

\subsection{Prehydrolysis}


2 The experimental conditions used for the autohydrolysis and for enzymatic prehydrolysis of

3 Miscanthus biomass were selected considering previous results (El Hage et al., 2010a) and

4 preliminary studies not reported here. The compositions of Miscanthus biomass and solid

5 residues after autohydrolysis and enzymatic hydrolysis are given in Table 1 . The untreated

6 Miscanthus biomass consisted of $\sim 49 \%$ glucans, $\sim 22 \%$ xylans, $\sim 2.5 \%$ of other sugars and

$7 \quad 25 \%$ lignins. As expected, the data concerning glucans and lignins in the solid residues show

8 that the autohydrolysis induced some degradation of cellulose and lignin whereas

9 hemicellulose polysaccharides (mainly xylans) were depolymerized; 63\% of the original

10 xylans were removed from the pulp and solubilized. In contrast, after enzymatic hydrolysis,

11 little impact of the treatment was observed on the composition of the resulting pulp. The

12 removal of $9 \%$ in weight of xylans and of glucans was observed demonstrating the xylosidase

13 and cellulase activities of the enzymatic cocktail. The soluble lignin and furans contents of the

14 two hydrolytic treatment solutions are given in Table 1. The mild conditions used for the

15 bioprocess produced lower content of soluble lignin and furans suggesting a very low

16 degradation of lignin and sugars.

17 Figures $1 \mathrm{~A}$ and $1 \mathrm{~B}$ give the sugars concentrations in the liquid phase as a function of the 18 duration of autohydrolysis and enzymatic hydrolysis respectively. The xylose concentrations 19 were higher than those of other sugars and reach a maximum at $\sim 8 \mathrm{~h}$ (Figure 1A). As 20 previously described, a further increase in the residence time led to a decrease in the recovery 21 of xylose, owing to degradation reactions (El Hage et al., 2010a). In contrast to the 22 hemicellulose components, glucans essentially remained in the solid phase and the 23 solubilisation of $\sim 4 \%$ of glucans was observed after $15 \mathrm{~h}$ of treatment. The sugar recovery 24 during enzymatic hydrolysis displayed a totally different pattern (Figure 1B). A very good 25 selectivity of hydrolysis toward glucans and xylans was observed with formation of 
1 monomeric sugars. Very low arabinose, galactose and mannose contents were detected in the

2 liquid phase. The concentrations of xylose and cellulose increased to reach a maximum after $310 \mathrm{~h}$.

4 Using SEM, the microscopic surfaces of untreated and pretreated pulp fibers were compared.

5 The examination showed differences between fibres. Untreated pulp fibres and enzymatically 6 hydrolysed fibres had an intact and smooth surface and well-defined folds whereas 7 autohydrolysed material exhibited smaller fibres with a disrupted surface with small tears and 8 holes (Supplementary materials). This observation could be attributed to a preferential 9 removal of hemicelluloses during the autohydrolysis step and/or cellulose chain scissions 10 within the fibril structure.

11 Gel Permeation Chromatography (GPC) has been shown to be a valuable tool in monitoring 12 the degradation of cellulose (Barth and Regnier, 1980, Foston and Ragauskas, 2010). Thus, 13 the question as to whether the autohydrolysis and the enzymatic treatment caused some 14 cellulose depolymerization was addressed by investigating the GPC elution curves of cellulose samples isolated from the solid residue recovered after treatment and modified with phenylisocyanate before analysis. The cellulose fractions after autohydrolysis had a weight average $\left(\mathrm{Mw}=518 \times 10^{3}\right)$ and a number average $\left(\mathrm{Mn}=108 \times 10^{3}\right)$ molecular weight

18 significantly lower than those of cellulose after enzymatic pretreatment $\left(\mathrm{Mw}=640 \times 10^{3}\right.$ and $19 \mathrm{Mn}=183 \times 10^{3}$ ). In addition, the value of polydispersity was higher after hydrolysis than after an enzymatic treatment (Mw/Mn 4.81 and 3.51, respectively). These results show that

21 the autohydrolysis conditions reduced the cellulose molecular mass by chain scissions within 22 the fibril structure. This result is in accordance with the microscopic study and with previous studies which proposed spatially localized hydrolysis in the amorphous regions during acidic 24 hydrolysis of cellulose (Foston and Ragauskas, 2010). The data of native cellulose showed 25 that enzymatic hydrolysis did not significantly change the cellulose molecular mass 
1 distributions. This result is in agreement with those from previous studies which suggested

2 that the cellulases work ablatively on cellulose microfibril surfaces, consuming the less

3 ordered surface layers of cellulose (Park et al., 2010, Hall et al., 2010).

4

\subsection{Ethanol organosolv treatment}

6 Results, including the composition of the pulps in terms of sugars, Klason lignin, amount of 7 organosolv lignin, content of furans and soluble lignin in the liquid phases are given in the 8 Supplementary Materials. Starting with raw Miscanthus biomass, the organosolv treatment 9 performed at low severity treatment (O1 and O2, Table 2) did not act as an effective solubilizer of lignin but by increasing the severity (higher reaction time, higher sulfuric acid

11 concentration), a larger part of lignin can be extracted (O3 and O4). As previously 12 demonstrated starting from empty palm fruit bunch (Chun Sheng et al., 2011), a critical concentration of hydronium ions $(1 \% \mathrm{w} / \mathrm{w})$ seems to be required to obtain an efficient hydrolysis and a subsequent solubilization of lignin fragments during an ethanol organosolv pretreatment.

Starting with autohydrolysed material $(\mathrm{A}+\mathrm{O})$, a larger part of lignin can be extracted during organosolv treatment than especially when using low sulfuric acid concentrations $(\mathrm{A}+\mathrm{O} 1$ and $\mathrm{A}+\mathrm{O} 2$ ). As previously described, after autohydrolysis, organosolv pulping of miscanthus is accelerated and the solubility of lignin in organic solvent is increased (El Hage et al., 2010). When the ethanol organosolv treatment was performed starting with solid materials recovered 21 after enzymatic hydrolysis, better results were obtained in terms of delignification. In these conditions, the critical parameter was the temperature of the organosolv treatment and the best results were observed at $170^{\circ} \mathrm{C}$. Thus pulps with very low lignin contents $(<2 \%)$ were

24 isolated even using low severity conditions for the organosolv step $\left(\mathrm{E}+\mathrm{O} 1, \mathrm{~T}=170^{\circ} \mathrm{C}\right)$. 


\section{$1 \quad$ 3.3. Organosolv lignins analysis}

2 Three organosolv lignin fractions isolated from the raw miscanthus $(\mathrm{O} 2)$ after the two-steps 3 processes $(\mathrm{A}+\mathrm{O} 2$ and $\mathrm{E}+\mathrm{O} 2)$ using the same organosolv conditions $(\mathrm{t}=60 \mathrm{~min}$, sulfuric 4 acid concentration $=0.5 \%, \mathrm{~T}=150^{\circ} \mathrm{C}$ ) were analyzed and compared in order to obtain a 5 more complete picture of the lignin changes occurring during the prehydrolysis steps. The 6 results are given in the Table 3.

\subsubsection{Molecular weight}

9 The weight average (Mw) and number average (Mn) molecular weight of the three organosolv lignin fractions were computed from their chromatograms. After enzymatic hydrolysis $(\mathrm{E}+$ $\mathrm{O} 2), \mathrm{Mw}$ and $\mathrm{Mn}$ of the organosolv lignins were clearly lower than those of the other fractions $(\mathrm{O} 2$ and $\mathrm{A}+\mathrm{O} 2)$. These results indicated that enzymatic prehydrolysis facilitated extensive cleavage of some inter-unit bonds in lignin during the organosolv treatment, producing smaller fragments. Moreover, a good correlation was observed between the molecular mass of lignin and the lignin organosolv extractability (see Figure 2).

\subsection{2. ${ }^{13} \mathrm{C} \mathrm{NMR}$}

18 The quantitative ${ }^{13} \mathrm{C}$ NMR spectra of the three organosolv lignin fractions are given in Supplementary Materials. Based on previous data (El Hage et al., 2009, 2010b), Table 3 gives the signal assignments in the spectra and the quantification of the signals. The integral values

21 for the structural moieties are reported per aryl group. The aromatic region of the ${ }^{13} \mathrm{C} \mathrm{NMR}$ spectra can be divided into three regions of interest: the protonated aromatics $(\delta 123-106$ ppm), condensed aromatics ( $\delta 140-123 \mathrm{ppm})$ and oxygenated aromatics ( $\delta 154-140 \mathrm{ppm})$.

24 Since the oxygenated aromatic and condensed aromatic regions have some degrees of overlap, 25 calculation of the degree of condensation is less precise when using these regions; however, a 
1 comparison of the integration values of these three regions can provide some information on

2 the degree of condensation of the lignin fractions. As can be seen in Table 3, the lignin

3 recovered after an autohydrolysis step $(\mathrm{A}+\mathrm{O} 2)$ exhibited a higher number of condensed

4 aromatic carbons and a lower number of protonated aromatic carbons per aromatic ring. This

5 observation translates to an increase in the degree of condensation during hydrothermal

6 treatment.

7 The aliphatic region (89-61 ppm) of the ${ }^{13} \mathrm{C}$ NMR spectra displays signals arising from the 8 aliphatic $\mathrm{C}-\mathrm{O}$ on the lignin propyl side chain. $\mathrm{C} \alpha, \mathrm{C} \beta$, and $\mathrm{C} \gamma$ can be identified in the regions

9 73-71, 89-78, and 64-61 ppm, respectively (Table 3). O2 and A + O2 displayed a strong

10 decrease of aliphatic $\mathrm{C}-\mathrm{O}$ with respectively 0.8 and $1.1 \mathrm{C}$ per aryl group compared to $2.6 \mathrm{C}$

11 per aryl for $\mathrm{E}+\mathrm{O} 2$. This observation suggested that starting from the biotreated pulp, the

12 deconstruction of lignin during the organosolv pulping occurred through $\beta-\mathrm{O}-4$ solvolytic

13 cleavages under mild conditions without further dehydration reactions or formation of

14 Hibbert's ketones.

\section{$16 \quad 3.3 .3 .{ }^{31} \mathrm{P}$ NMR}

17 Data from the quantitative ${ }^{31} \mathrm{P}$ NMR spectra of the three lignin samples, obtained following their derivatization with TMDP, are presented in Table 3. The concentration of each hydroxyl

19 functional group (in mmol.g ${ }^{-1}$ ) was calculated on the basis of the hydroxyl content of the 20 internal standard cyclohexanol and its integrated peak area (Granata and Argyropoulos, 1995).

21 Lower concentration of aliphatic $\mathrm{OH}$ groups and higher concentration of phenolic $\mathrm{OH}$ groups 22 were observed for $\mathrm{A}+\mathrm{O} 2$. This observation could be rationalized by an extensive 23 depolymerization of lignin during the autohydrolysis step with $\beta-\mathrm{O}-4$ scissions producing 
1 phenolic $\mathrm{OH}$ groups and subsequent dehydration reactions through acid-catalysed elimination reactions.

\subsection{Cellulose-to-Glucose conversion}

The cellulose-to-glucose conversion after $72 \mathrm{~h}$ given in Fig. 3 and 4 shows the conversion

6 yields at different time points during the experiments starting from 6 pulps : raw material

7 (RM), prehydrolysed materials ( $\mathrm{A}$ and $\mathrm{E})$ and organosolv pulps $(\mathrm{O} 2, \mathrm{~A}+\mathrm{O} 2, \mathrm{E}+\mathrm{O} 2)$. Raw Miscanthus (RM) and prehydrolysed materials (A and E) showed a low to very low cellulose-to-glucose conversion. By means of the organosolv treatment, cellulose became more amenable to enzymatic hydrolysis in the order: $\mathrm{O}<\mathrm{A}+\mathrm{O}<\mathrm{E}+\mathrm{O}$. A very good

11 correlation can be established between Klason lignin content of the cellulosic pulps and their 12 hydrolysability by enzymes. Thus, without prehydrolysis and using low severity organosolv conditions, most of the lignin remained in the resulting pulp which continued to be very resistant to enzymatic hydrolysis. Using a two-steps process enzymatic prehydrolysis and subsequent organosolv treatment, very low lignin content in the pulps were associated to good conversion yields, even using mild organosolv conditions (e.g., E + O1).

\subsection{Discussion}

The two steps processes involving a prior fractionation of the hemicelluloses have a dual aim: not only a better hemicelluloses sugars recovery but also the optimisation of the subsequent aqueous-ethanol delignification step. Based on the results presented above and on previously described studies (El Hage et al., 2010a), the lignin deconstruction during the hydrothermal treatment increases its extractability during the organosolv treatment through the cleavage of lignin-carbohydrate bonds and the formation of small fragments of lignin. In the same time this lignin deconstruction is associated with re-polymerization reactions through formation of 
1 new $\mathrm{C}-\mathrm{C}$ linkages $(\beta-\beta, \beta-1$ and $\beta-5)$. These condensation reactions result in negative effects

2 on lignin properties and impair the degree of delignification. As a consequence, a fraction of

3 the re-polymerized lignin in the biomass is difficult to extract, even using sever conditions

4 (Lora and Wayman 1978, Leschinsky et al., 2008).

5 The utilization of an industrial enzymatic cocktail (with cellulase and xylosidase activities)

6 for the prehydrolysis of Miscanthus biomass, despite a very low impact on the fibre structure

7 and composition, disrupted enough of the remaining polymers to enhance the removal of

8 lignin during the organosolv step to a large extend. The main reason explaining the enhanced

9 delignification could be the weakening of the lignin-holocellulose complex in mild conditions

10 facilitating depolymerisation of lignin (through the cleavage of aryl-ether bonds) during the

11 ethanolysis and leading to the formation of small, easy removable fragments. As a result, very

12 mild conditions were required for the organosolv delignification step to obtain a good

13 solubilisation of the disrupted lignin leading to cellulosic pulps with very low lignin content.

14 Table 2 lists the organosolv conditions for Miscanthus pretreatment optimized for one- and

15 two-steps processes, the lignin contents of the residual pulps, the furans content in the liquid

16 phase and the combined severity parameters of each organosolv treatment. Combined severity

17 correlation has been described to be an efficient tool to evaluate and compare pretreatments as

18 a function of the reaction time, the temperature and the $\mathrm{pH}$ of the medium (Chun Sheng, 2011

19 ; Brosse et al., 2009, 2010). It clearly appears that when starting from a biotreated material, a

20 lower process severity was required for better lignin removal from the pulp. Interestingly, the

21 mild organosolv conditions used starting from biotreated material clearly produce a lower

22 concentration of furans (degradation products). Nevertheless, in order to make this process

23 cost effective, further studies are required to optimize the enzymatic step and to reduce the

24 amount of enzyme cocktail during pretreatment. 


\section{4. Conclusion}

2 Enzymatic pre-hydrolysis was assessed as a first step in a pretreatment process of Miscanthus

3 biomass involving an aqueous-ethanol organosolv treatment. Despite a very low impact on

4 fibre structure and composition, the enzymatic pre-treatement disrupted enough of the

5 lignocellulosic matrix to enhance removal of lignin and hydrolysability of the cellulosic pulp

6 for the production of monomeric glucose. The purpose of this process is to facilitate the

7 separation of lignocellulosic components during the delignification step ; however further

8 evaluations are required to determine the specific action of the enzymatic step and the

9 effective global energy input in the whole process.

Appendix. Supplementary data

Supplementary data associated with this article can be found, in the online version

Acknowledgements

The authors gratefully acknowledge IFR110 EFABA and CPER 2007-2013 "Structuration du

Pôle de Compétitivité Fibres Grand'Est” (Competitiveness Fibre Cluster), through regional supports.

\section{References}

Barth H, Regnier F., 1980. High-performance gel permeation chromatography of watersoluble cellulosics. J Chromatogr 192:275-93.

Brodeur,G., Yau, E., Badal, K., Collier, J. Ramachandran, K.B., Ramakrishnan, S., 2011. Chemical and Physicochemical Pretreatment of Lignocellulosic Biomass: A Review SAGE-Hindawi Access to Research Enzyme Research, Article ID 787532, 17 pages

Brosse, N., Sannigrahi, P., Ragauskas, A., 2009. Pretreatment of Miscanthus x giganteus using the ethanol organosolv process for ethanol Production. Ind. Eng. Chem. Res. 48, 8328-8334. 
Brosse, N., El Hage, R., Sannigrahi, P., Ragauskas, A., 2010. Dilute Sulphuric Acid and Ethanol Organosolv Pretreatment of Miscanthus x Giganteus. Cellulose Chemistry and Technology. 44 (1-3), 71-78.

Chun Sheng G., Hui Teng T., Keat Teong L., Brosse N, 2011. Evaluation and optimization of organosolv pretreatment using combined severity factors and Response surface methodology, Biomass Bioener, in press

El Hage, R., Brosse, N., Chrusciel, L., Sanchez, C., Sannigrahi, P., Ragauskas, A., 2009. Characterization of milled wood lignin and ethanol organosolv lignin from Miscanthus. Polym. Degrad. Stab. 94, 1632-1638.

El Hage, R., Chrusciel, L., Desharnais, L., Brosse, N., 2010a. Effect of Autohydrolysis of Miscanthus x giganteus on Lignin Structure and Organosolv Delignification. Bioressour. Technol., 101, 9321-9329.

El Hage, R., Brosse, N., Sannigrahi, P., Ragauskas, A., 2010b. Effect of the Severity of the Ethanol Organosolv Process on the Chemical Structure of Ethanol Organosolv Miscanthus Lignins, Polymer Degrad. Stab., 95, 997-1003.

FitzPatrick, M., Champagne, P., Cunningham M.F., Whitney, R.A., 2010. A biorefinery processing perspective: Treatment of lignocellulosic materials for the production of valueadded products Bioresource Technology 101, 8915-8922.

Foston, M., Ragauskas, A.J., 2010. Changes in lignocellulosic supramolecular and ultrastructure during dilute acid pretreatment of Populus and switchgrass Biomass and bio energy 34, 1885- 1895

Garrote, G., Dominguez, H., Parajo, J.C., 2001. Generation of xylose solutions from eucalyptus globulus wood by autohydrolysis-posthydrolysis processes: posthydrolysis kinetics. Bioresour. Technol. 79 (2), 155-164.

Garrote, G., Dominguez, H., Parajo, J.C., 2002. Autohydrolysis of corncob: study of nonisothermal operation for xylooligosaccharide production. Journal of Food Engineering 52, 211-218.

Ghose, T.K., 1987. Measurement of cellulase activities. Pure \& Appl. Chem. 59(2), 257-268.

Granata, A., Argyropoulos, D.S., 1995. 2-chloro-4,4,5,5-tetramethyl-1,3,2dioxaphospholane, a reagent for the accurate determination of the uncondensed and condensed phenolic moieties in lignins. J Agric Food Chem. 43, 1538-1544.

Hall, M., Bansal, P., Lee, J.H., Realff, M.J., and Bommarius A.S., 2010. Cellulose crystallinity - a key predictor of the enzymatic hydrolysis rate. FEBS Journal, 277, 15711582.

Katzen, R., Schell, D.J., 2006. Lignocellulosic feedstock biorefinery: history and plant development for biomass hydrolysis. Biorefineries-Industrial Processes and Products, 1, 129-138.

Lee, J.M., Shi, J., Venditti, R.A., Jameel, H., 2009. Autohydrolysis pretreatment of Coastal Bermuda grass for increased enzyme hydrolysis. Bioresource Technology 100, 64346441.

Leschinsky, M., Zuckerstatter, G., Weber, H.K., Patt, R., Sixta, H., 2008. Effect of autohydrolysis of Eucalyptus globulus wood on lignin structure. Part 1 : Comparison of different lignin fractions formed during water prehydrolysis. Holzforschung. 62, 645-652

Lin, S.Y., Dence C.X., 1992. "Methods in Lignin Chemistry", Springer Series in Wood Science, Springer-Verlag Berlin, Heidelberg.

Lora, J.H., Wayman, L., 1978. Delignification of hardwoods by autohydrolysis and extraction. 61, 47-50.

Martinez, A., Rodriguez, M.E., York, S.W., Preston, J.F., Ingram, L.O., 2000. Use of UV absorbance to monitor furans in dilute acid hydrolysates of biomass. Biotechnol. Prog. $16(4), 637-641$. 
Munoz, C., Mendonc, R., Baeza J., Berlin, A., Saddler, J., Freer, J., 2007. Bioethanol production from bioorganosolv pulps of Pinus radiata and Acacia dealbata $\mathrm{J}$ Chem Technol Biotechnol 82, 767-774.

Palmqvist, E., Hahn-Hagerdal, B., 2000. Fermentation of lignocellulosic hydrolysates. II: inhibitors and mechanisms of inhibition. Bioresour. Technol. 75, 25-33.Pan, X., Kadla, J.F., Ehara, K., Gilkes, N., Saddler, J.N., 2006. Organosolv ethanol lignin from hybrid poplar as a radical scavenger: relationship between lignin structure extraction conditions and antioxidant activity. J. Agric. Food Chem. 54, 5806-5813.

Pan, X.J.,, Xie, D., Yu, R.W., Lam, D., Saddler, J.N., 2007. Pretreatment of lodgepole pine killed by mountain pine beetle using the ethanol organosolv process: Fractionation and process optimization. Ind Eng Chem Res. 46(8), 2609-2617.

Park,S., Baker, J.O., Himmel,M.E., Parilla, P.A., Johnson, D.K., 2010. Biotechnol. Biofuels 3, 10.

Patel, D.P., Varshney, A.K., 1989. The effect of presoaking and prehydrolysis on the organosolv delignification of bagasse. Indian J. Technol. 27(6) 285-288.

Söderstroem, J.; Pilcher, L. ; Galbe, M.; Zacchi, G., 2003. Two-step steam pretreatment of softwood by dilute $\mathrm{H}_{2} \mathrm{SO}_{4}$ impregnation for ethanol production. Biomass and Bioenergy. $24,475-486$.

Somogyi, M., 1952. Notes on sugar determination. J. Biol. Chem. 195, 19-23.

Thomsen, M.H., Thygesen, A., Thomsen, A. B., 2009. Identification and characterization of fermentation inhibitors formed during hydrothermal treatment and following SSF of wheat straw. Applied Microbiol. Biotechnol. 83(3), 447-455. 
Figure 1 Composition of the hydrolysates (sugar contents) as a function of the residence time of autohydrolysis and enzymatic hydrolysis treatments. ${ }^{\text {a }}$

5

6

7

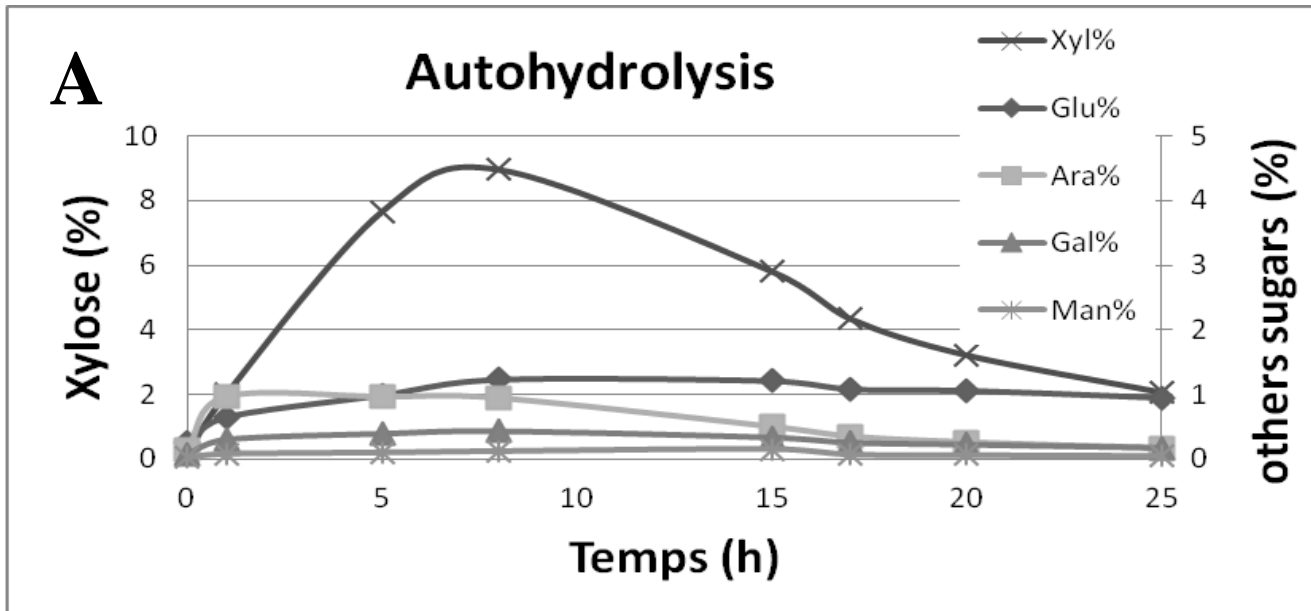

B Enzymatic Hydrolysis

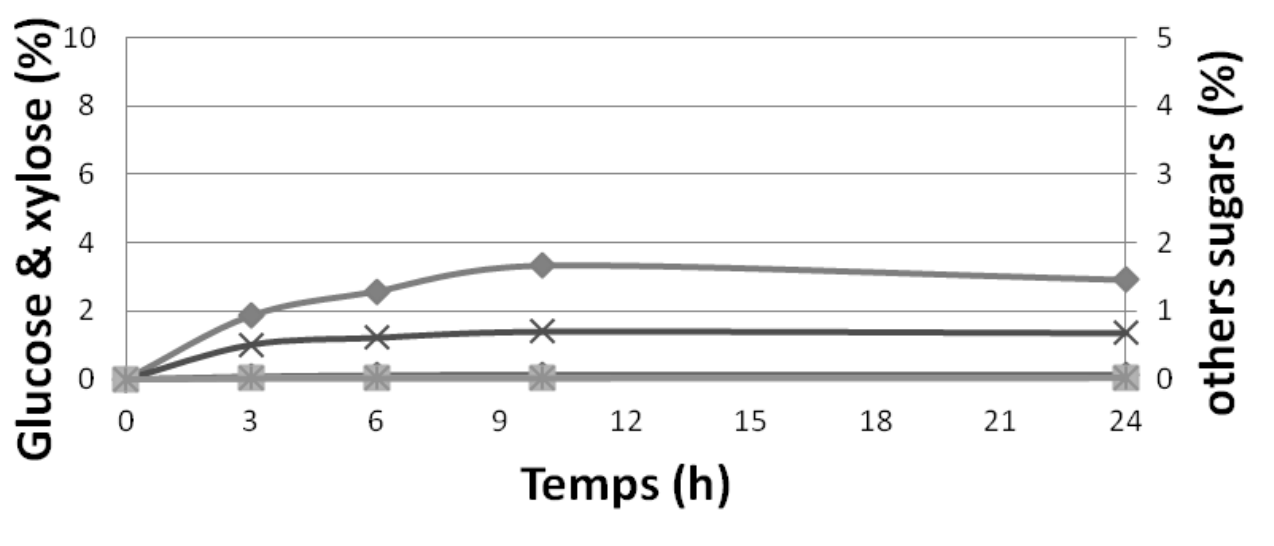

${ }^{a}$ All data are given as a percentage (w/w) with respect to initial weight of miscanthus. 
Figure 2 Klason lignin contents in the raw Miscanthus biomass and in pulps.

4

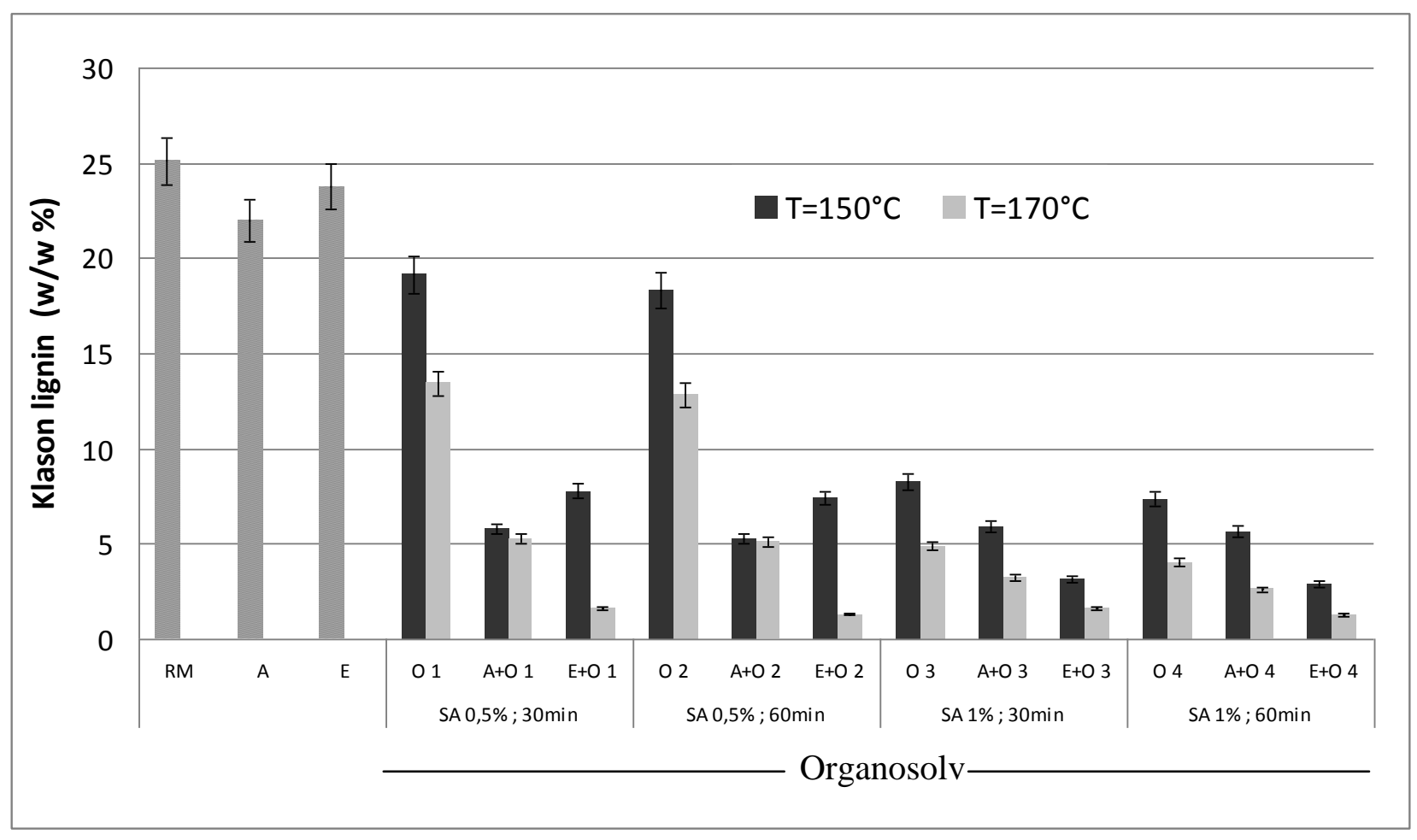

$\mathrm{RM}=$ Raw Material $; \mathrm{A}=$ autohydrolysis $; \mathrm{E}=$ Enzymatic hydrolysis $; \mathrm{O}=$ ethanol Organosolv treatment performed at $150^{\circ} \mathrm{C}$ and $170^{\circ} \mathrm{C}$. Error bars represent standard deviations.

10

11

12

13

14

15

16

17

18 
1 Figure 3 Cellulose-to-Glucose conversion ${ }^{\mathrm{a}}$ of pulps after organosolv treatments

2

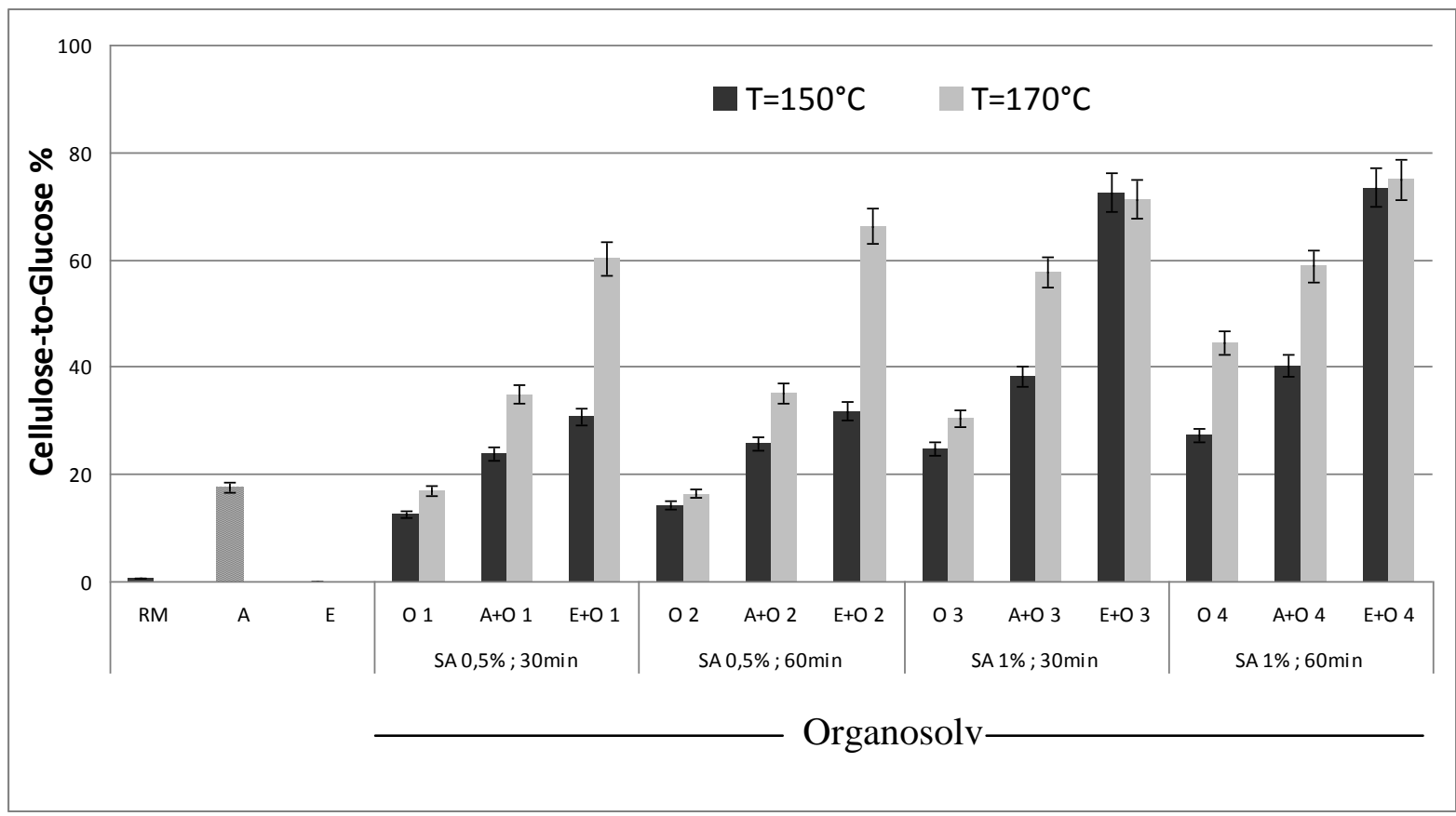

4 a Cellulose conversion to monomeric glucose, based on glucose content in the pulps. $5 \quad \mathrm{RM}=$ Raw Material ; $\mathrm{A}=$ Autohydrolysis ; $\mathrm{E}=$ Enzymatic hydrolysis ; $\mathrm{O}=$ ethanol 6 Organosolv treatment performed at $150^{\circ} \mathrm{C}$ and $170^{\circ} \mathrm{C}$. Error bars represent standard 7 deviations 
1 Figure 4 Cellulose-to-Glucose conversion $(\%)^{\mathrm{a}}$ at different time points for 6 pulps ${ }^{\mathrm{b}}$ 2

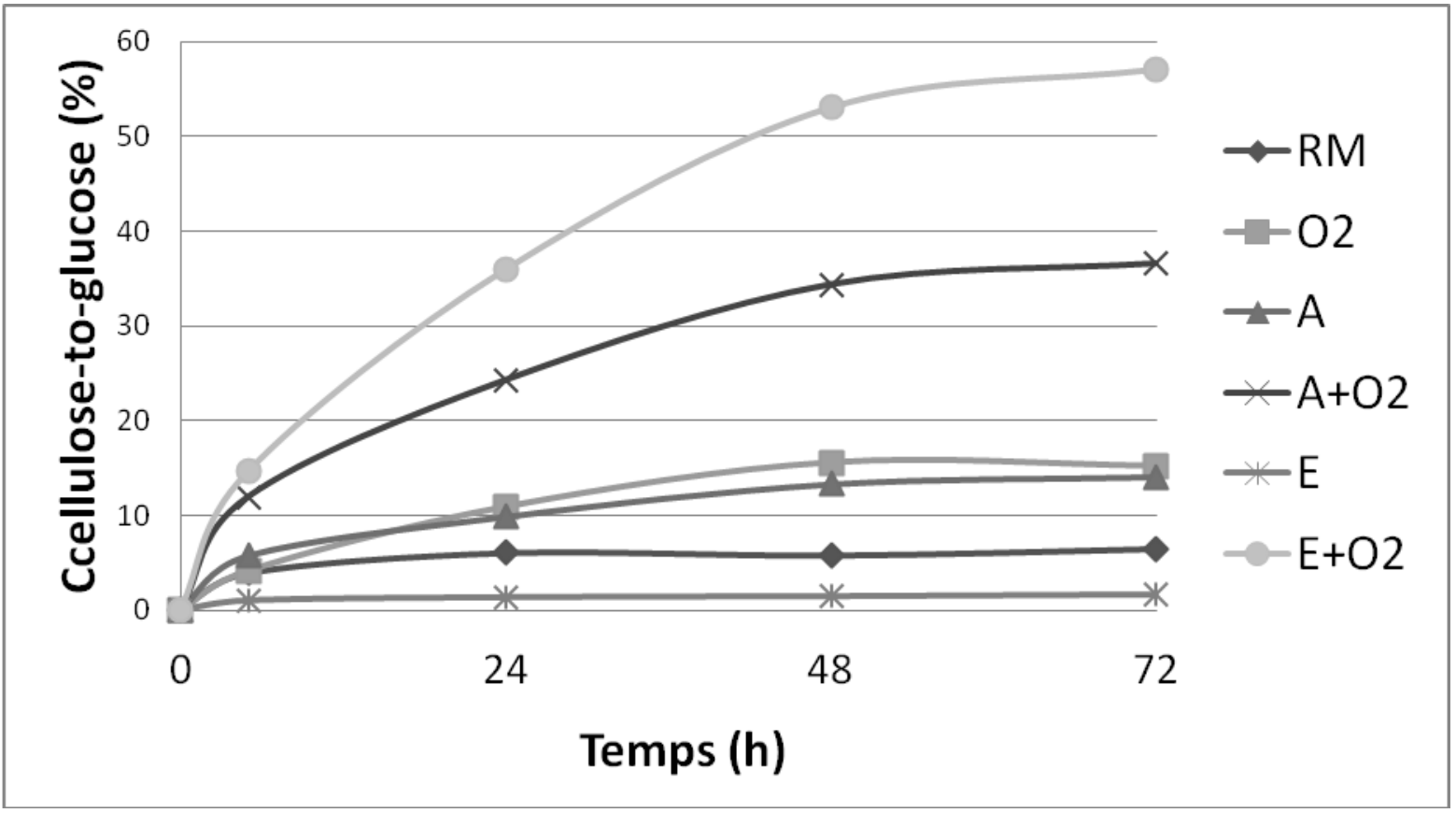

${ }^{\mathrm{a}}$ Cellulose conversion to monomeric glucose, based on glucose content in the pulps.

${ }^{\mathrm{b}} \mathrm{RM}=$ raw material ; O2 : organosolv pretreatment (experimental conditions see Figure 3$)$; $\mathrm{A}=$ autohydrolysis $; \mathrm{E}=$ enzymatic prehydrolysis 
2 Table 1 Composition ${ }^{\mathrm{a}}$ of Miscanthus biomass, solid residue after autohydrolysis and 3 enzymatic hydrolysis. Composition ${ }^{\mathrm{a}}$ of soluble fractions after prehydrolysis.

4

5 all data are yields of components(g) per 100g of oven-dried Miscanthus; values in parentheses correspond to

\begin{tabular}{|c|c|c|c|c|c|c|c|c|c|}
\hline \multirow[t]{2}{*}{ Prehydrolysis } & \multicolumn{7}{|c|}{ Solid residues } & \multicolumn{2}{|c|}{ Aqueous phase } \\
\hline & Glc\% & Xyl\% & Ara\% & Gal\% & Man\% & $K^{b}{ }^{\mathbf{b}} \%$ & $\mathrm{SL}^{\mathrm{c} \%}$ & SL\% & Furans \% \\
\hline Without & $\begin{array}{c}49,09 \\
(0,6)\end{array}$ & $\begin{array}{c}21,65 \\
(0,5)\end{array}$ & $\begin{array}{c}1,83 \\
(0,03)\end{array}$ & $\begin{array}{c}0,43 \\
(0,01)\end{array}$ & $\begin{array}{c}0,27 \\
(0,01)\end{array}$ & $\begin{array}{l}25,11 \\
(0,35)\end{array}$ & $\begin{array}{c}1,65 \\
(0,83)\end{array}$ & - & \\
\hline Autohydrolysis & $\begin{array}{c}48,09 \\
(0,9)\end{array}$ & $\begin{array}{l}8,13 \\
(0,8)\end{array}$ & $\begin{array}{c}0,19 \\
(0,01)\end{array}$ & $\begin{array}{c}0,07 \\
(0,01)\end{array}$ & $\begin{array}{c}0,11 \\
(0,01)\end{array}$ & $\begin{array}{l}22,01 \\
(0,85)\end{array}$ & $\begin{array}{c}0,65 \\
(0,13)\end{array}$ & $\begin{array}{c}2,53 \\
(0,11)\end{array}$ & $\begin{array}{c}1,52 \\
(0,09)\end{array}$ \\
\hline Enzyme & $\begin{array}{l}45,5 \\
(0,5)\end{array}$ & $\begin{array}{c}19,73 \\
(0,9)\end{array}$ & $\begin{array}{c}1,69 \\
(0,04)\end{array}$ & $\begin{array}{c}0,33 \\
(0,02)\end{array}$ & $\begin{array}{c}0,19 \\
(0,01)\end{array}$ & $\begin{array}{l}23,19 \\
(0,68)\end{array}$ & $\begin{array}{c}0,85 \\
(0,31)\end{array}$ & $\begin{array}{c}1,26 \\
(0,18)\end{array}$ & $\begin{array}{c}0,02 \\
(0,02)\end{array}$ \\
\hline
\end{tabular}

6 the standard error established from three independent experiments ; ${ }^{b}$ Klason lignin (including ashes) ; ${ }^{\mathrm{c}}$ soluble 7 lignin 
1 Table 2. Organosolv conditions with combined severity parameters for one- or two-steps

2 processes and Klason lignin content of the pulps

\begin{tabular}{|c|c|c|c|c|}
\hline Prehydrolysis $^{\circ}$ & Organosolv conditions $^{\text {Combined severity }}{ }^{\mathbf{a}}$ & Klason lignin $^{\mathbf{b}}$ & Furans $^{\mathbf{b}}$ \\
\hline Without $^{\mathrm{c}}$ & $190^{\circ} \mathrm{C}, \mathrm{H}_{2} \mathrm{SO}_{4} 1.2 \%, 60 \mathrm{~min}$ & 2.77 & $5.1 \%$ & $1.9 \%$ \\
\hline Autohydrolysis & $170^{\circ} \mathrm{C}, \mathrm{H}_{2} \mathrm{SO}_{4} 1 \%, 60 \mathrm{~min}$ & 1.80 & $2.6 \%$ & $2.36 \%$ \\
\hline Enzyme & $\mathbf{1 7 0}^{\circ} \mathbf{C}, \mathbf{H}_{2} \mathbf{S O}_{\mathbf{4}} \mathbf{0 . 5 \%}, \mathbf{3 0 m i n}$ & $\mathbf{1 . 4 6}$ & $\mathbf{1 . 3 \%}$ & $\mathbf{0 . 6 \%}$ \\
\hline
\end{tabular}

$3{ }^{\mathrm{a}} \log \left(\mathrm{R}_{0}\right)-\mathrm{pH}, \mathrm{R}_{0}=$ t.exp $\left(\mathrm{T}-\mathrm{T}_{\text {ref }}\right) / 14.7, \mathrm{~T}_{\text {ref }}=100^{\circ} \mathrm{C} ;{ }^{\mathrm{b}}$ yields based on dry weight of raw miscanthus ; ${ }^{\mathrm{c}}$ Brosse et 4 al, 2009.

5 
2 Table 3. Organosolv lignins characterization by GPC, by ${ }^{13} \mathrm{C}$ NMR and by ${ }^{31} \mathrm{P}$ NMR.,

\begin{tabular}{|c|c|c|c|c|c|}
\hline \multirow{2}{*}{\multicolumn{3}{|c|}{ 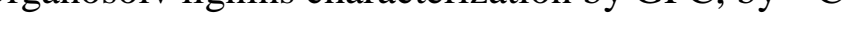 }} & \\
\hline & & & $\mathbf{O 2} 2^{\mathbf{a}}$ & $\mathrm{A}+\mathrm{O2}^{\mathrm{a}}$ & $\mathrm{E}+\mathrm{O2}^{\mathrm{c}}$ \\
\hline \multirow{3}{*}{ GPC } & & $\mathrm{Mw}^{\mathrm{d}}$ & 5715 & 5103 & 4281 \\
\hline & & $\mathrm{Mn}^{\mathrm{e}}$ & 1932 & 1496 & 1316 \\
\hline & & Ip $(\mathrm{Mw} / \mathrm{Mn})^{\mathrm{f}}$ & 2.96 & 3.41 & 3.25 \\
\hline \multicolumn{2}{|r|}{ ppm } & NMR assignments & \multicolumn{3}{|c|}{ in number of carbon per aryl ${ }^{\mathbf{g}}$} \\
\hline \multirow{7}{*}{${ }^{13} \mathrm{C}$ NMR } & $155-142$ & Aromatic C-O & 1.8 & 1.9 & 1.7 \\
\hline & $142-124$ & Aromatic C-C & 2.0 & 2.1 & 2.0 \\
\hline & 124-102 & Aromatic C-H & 2.3 & 2.1 & 2.3 \\
\hline & $89-78$ & $\mathrm{C} \beta$ in $\beta-\mathrm{O}-4, \mathrm{C} \alpha$ in $\beta-5$ et $\beta-\beta$ & 0.2 & 0.3 & 0.9 \\
\hline & $73-71$ & $\mathrm{C} \alpha$ in $\beta-\mathrm{O}-4$ & 0.4 & 0.3 & 0.7 \\
\hline & $64-61$ & $\mathrm{C}-\gamma$ & 0.2 & 0.5 & 1.0 \\
\hline & 56 & $\mathrm{OMe}$ & 1.2 & 1.0 & 1.1 \\
\hline \multicolumn{2}{|r|}{ ppm } & NMR assignments ${ }^{h}$ & \multicolumn{3}{|c|}{ in $\mathrm{mmol} / \mathrm{g}$, } \\
\hline \multirow{7}{*}{${ }^{31} \mathbf{P}$ NMR } & $145.5-150.0$ & $\mathrm{OH}$ aliphatic & 1.73 & 0.94 & \multirow[t]{2}{*}{1.36} \\
\hline & 144.9 & OH cyclohexanol & 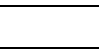 & \multirow[b]{2}{*}{1.37} & \\
\hline & $136.5-144.5$ & Phénols & 0.91 & & 1.17 \\
\hline & $141.8-143.5$ & OH syringyle & 0.28 & 0.55 & 0.43 \\
\hline & $138.7-140.1$ & OH guaiacyle & 0.38 & 0.53 & 0.45 \\
\hline & $137.2-138.1$ & OH p-hydroxyphenyle & 0.25 & 0.29 & 0.29 \\
\hline & $134.0-135.7$ & Carboxylic acid & 0.02 & 0.07 & 0.05 \\
\hline
\end{tabular}

${ }^{\mathrm{a}}$ see Figure 3, $\mathrm{O}=$ organosolv lignin extracted from raw miscanthus ; ${ }^{\mathrm{b}} \mathrm{A}=$ organosolv lignin extracted from residue after autohydrolysis ; ${ }^{\mathrm{c}} \mathrm{E}=$ organosolv lignin extracted from residue after enzymatic hydrolysis ; ${ }^{\mathrm{d}}$ weight average molecular weight ; ${ }^{\mathrm{e}}$ number average molecular weight ; ${ }^{\mathrm{f}}$ polydispersity $\mathrm{Mw} / \mathrm{Mn} ;{ }^{\mathrm{g}}$ determined by integration; ${ }^{\mathrm{h}}$ lignin samples phosphorylated with 2-chloro-4,4,5,5-tetramethyl-1,2,3-dioxaphospholane ; ${ }^{\mathrm{i}}$ determined by integration with cyclohexanol as an internal standard. 